\title{
"PITTSBURGHESE" ONLINE: VERNACULAR NORMING IN CONVERSATION
}

\author{
BARBARA JOHNSTONE \\ DAN BAUMGARDT \\ Carnegie Mellon University
}

$\mathrm{I}_{\mathrm{N}}$ conversation about regional dialect helps illuminate part of the relatively unstudied process of vernacular norm-formation (Milroy 1992, 81-122; Wolfram 2003). Our data is an online discussion of the speech of the Pittsburgh area. As the online discussion illustrates, vernacular normformation may involve discursive practices similar to those that result in language standardization. Like standardization (Milroy and Milroy 1985; Cameron 1995; Lippi-Green 1997), vernacular norm-formation of this sort is embedded in particular interactional, ideological, and historical contexts. In other words, (1) interactional: people who engage in talk about dialect have to do what it takes to claim and keep the conversational floor and successfully contribute to the activity at hand; (2) ideological: in doing so, they draw on and reshape local and supralocal ideas about language and dialect and their social meanings; and (3) historical: people are drawn to conversations such as this because of historical and economic developments impacting on their lives in ways that make them aware of and interested in local speech. Each of these sources of constraint on how dialect-normative talk is shaped plays a role in determining what the norms will be.

Our specific goal is to illustrate how each of these three types of context helps shape explicit norms for "Pittsburghese" in an online conversation prompted by the question "Is our local dialect charming or embarrassing?"

To illustrate the role of interactional processes, we explore several ways in which participants in the discussion claim the authority to speak. We show that the need to show that one is a legitimate contributor to the discussion results in a great deal of "feature-dropping," as participants show that they have the right to evaluate local speech by displaying their knowledge of it-thus reinforcing popular beliefs about what "Pittsburghese" is and suggesting new norms. Participants also find feature-dropping useful in building rapport with fellow participants and in making evaluative 
arguments about the dialect, its speakers, and the region. In some cases, these interactional demands lead to an activity we call "vernacular lexicography," or explicit talk about what should be included in the dialect and why.

To illustrate the role of ideology, we explore how the structure of the conversation as a whole, as well as the structure of particular contributions to it, draws on and reinforces widely shared ideas about how places, people, and dialects are "naturally" linked, and we show that arguments about what counts as local are supported with reference to local ideas about what constitutes local identity. We suggest that these ideas and the ways they are deployed in the discussion can result in some local features being more strongly identified with local speech than others.

To illustrate the role of history, we show how geographic mobility caused by local economic changes has contributed to the heightened awareness of local identity that makes people engage in norm-forming discourse like this in the first place. Geographic mobility shapes the resulting norms both by privileging dialect features that resonate with participants' nostalgia and by privileging forms that are easy to compare with forms heard where the participants now live.

Variationists have used talk about talk and performances of dialect as evidence about language attitudes (Preston 1989, 1999; Milroy 2001) and have explored their role in explaining the existence and extent of variation (Johnstone and Bean 1997; Lane 1998; Schilling-Estes 1998; Johnstone 1999; Coupland 2001; Dyer 2002) and as a potential source of data for studies of dialect forms (Montgomery and Mishoe 1999; Dubois and Horvath 2002). At least in a preliminary way, we have explored the role of overt representations of dialect in the process of change (Johnstone, Bhasin, and Wittkofski 2002). But variationists have paid much less attention to the details of the discursive practices in which such representations and performances arise, and we have not typically asked why people talk about or perform regional accents. These are important questions. Their answers shed light on the processes by which people come to share ideas about what constitutes a particular nonstandard way of speaking and what it means to speak that way. Our study elaborates the central claim of research in the "perceptual dialectology" tradition (Preston 1989, 1999) that folk ideas about language bear on the phenomena linguists are interested in-but it differs from much research in this tradition in several ways. For one thing, our analysis is not primarily aimed at gathering evidence about folk ideas about language. We are not interested here in the details of how our conversationalists characterize "Pittsburghese" or in the degree to which their characterization corresponds to what a linguist's might be. 
Rather, we are interested in the interactional, ideological, and historical factors that give rise to such conversations and shape how they proceed. Another difference is that we analyze naturally occurring data rather than the results of mapping or other experimental tasks or interviews.

Our data represents a relatively new and increasingly frequent discursive practice: anonymous online discussion among strangers. The conversation we look at was sparked by and, at least at first, oriented to a question posted on the Web site of a Pittsburgh television station, specifically eliciting people's attitudes about regional speech. The timing of the posting makes us think that it was suggested by a press release about a scholarly workshop on local speech that one of us was involved with, but we did not design this interaction in any way and, in fact, were unaware of it until several months after it started. Our data is thus naturally occurring discourse in a genre (talk about "Pittsburghese") that is very common in Pittsburgh. In this discussion, which we tracked for $9^{1 / 2}$ months, 101 people respond to a question asking their opinion about Pittsburgh speech and to each other's responses, for a total of 180 contributions.

\section{VERNACULAR SPEECH NORMS}

James Milroy (1992, 81-109) provides a detailed account of how "community norms" function as markers of regional or social identity and social differentiation within communities. Community norms arise when differences among variants come to have social meanings on which community members agree and of which they are often aware. Milroy shows how norms are enforced in dense, multiplex social networks, where "relatively close socializing patterns have the effect of maintaining traditional norms" (89), and how they weaken when they become dysfunctional for speakers with looser social networks. Milroy says little, however, about how social meaning gets attached to particular forms or about the particular processes through which agreement about the "consensus norm of usage" in a community arises.

As Wolfram (2003) points out, the processes leading to the development of norms for vernacular varieties are in general not well understood. One set of questions about vernacular norming has to do with what Wolfram refers to as the "embedding issue": How do linguistic features that co-vary with social ones ("indicators" in Labov's 1972 sense) come to index them (thus becoming "markers" or "stereotypes")? How, in other words, do forms or patterns of variability acquire the more or less shared social meanings Milroy describes? Another set of questions has to do with the 
"dynamic issue": "How have the norms of different vernaculars changed over time, and what social mechanisms are used to transmit and regulate these changing norms?" (Wolfram 2003, 253).

Wolfram suggests that vernacular norming processes are unlike the relatively well-described processes by which mainstream varieties are standardized. This is in part because vernacular norms arise in different, often more covert and informal discursive practices, with fewer designated "language guardians" like dictionary usage panelists and teachers and fewer designated occasions and sites for normative discourse like English classes, grammar hotlines, or the "complaint tradition" described by Milroy and Milroy (1985). "At this point," says Wolfram, "we know little about the regulatory procedures and mechanisms used to instantiate vernacular dialect norms" (253).

The conversation we describe in this paper represents a relatively overt, though very informal, procedure by which vernacular norms are proposed and enforced and their social meanings elaborated. In it, people make explicit and implicit claims and counterclaims about what counts as "our local dialect" and about the social meaning of particular features and of the variety as a whole. Much of the talk is not dissimilar in this respect to what happens on usage panels and in rhetoric handbooks. But the historical context of this talk and the interactional and ideological agendas of the participants are not the same as those that result in prestige standards. For example, while the authority of arbiters of prestige standards tends to be endowed by their institutional roles, the authority of participants in conversations like this has to be established in the course of the interaction. Further, while prestige standards are embedded in the agendas of nationalism and political power, talking about local talk is, as we will show, a resource for constructing community and place on a more local levelsometimes in contradistinction to nation-and for constructing personal identity-sometimes in contradistinction to citizenship.

As with more formal codifications of standard varieties, the connection between explicit linguistic norms of this kind and actual linguistic behavior is indirect. As Milroy and Milroy (1985) point out, standardization is the production of consciousness of the standard, not the production of actual uniformity of speech. If the existence of a relatively codified standard for written English actually guaranteed its use, for example, there would be no need for style guides, grammar hotlines, and the like. In fact, however, it is the idea that there is a completely codified, invariable standard, contrasted with everyday empirical evidence of variability, that sends writers to sources like these. 
Likewise, the kind of vernacular norm-formation we are exploring has to do with the production of the idea that there is a variety ("Pittsburghese") consisting of a particular set of words, structures, and sounds. It is the result of observed variability, not a description of or a cause of invariability. It is unlikely that any of the people involved in our conversation use all the features they collectively or even individually identify as "Pittsburghese," and some may not use any of them. We cannot say anything at this point about whether, or how, conversations like these affect the speech of people who do have local accents or use local-sounding words or structures. Consciousness of norms can, however, lead to change, and in further work we will explore whether this is happening in Pittsburgh.

\section{PITTSBURGH SPEECH AND "PITTSBURGHESE”}

When Pittsburghers talk about themselves, they often talk about local speech. There is a long-standing tradition of attention to "our local dialect" (in the words of the Web site where our conversation took place) of which this conversation is only a recent example (Johnstone and Danielson 2001). Since at least the 1960s, this imagined dialect has been called "Pittsburghese." (As a reminder that "Pittsburghese" is not a technical term, we use it in quotation marks.) From the point of view of linguistics there is no "dialect" (no matter how dialect areas are delimited) that is spoken only in Pittsburgh or in the Pittsburgh metropolitan area. However, local linguistic and cultural history encourages the idea that "Pittsburghese" is unique to the city and the immediate area.

Pittsburgh is in southwestern Pennsylvania, on the western edge of what Pittsburghers (along with most other Americans) think of as the Northeast, but across the Allegheny Mountains from the East Coast. Partly because of the city's historical geographic isolation from eastern Pennsylvania and other large eastern cities, along with perceived differences between Pittsburghers and people from nearby Ohio, Maryland, and West Virginia, Pittsburghers tend to identify with the city rather than with the state or the region (Zelinsky 1995). This helps account for their belief that the local vernacular dialect is unique to Pittsburgh or to the immediate area.

Local social and economic history has also encouraged the belief that "Pittsburghese" is unique and interesting. Articles about the unique quirks of local speech have appeared in the Pittsburgh newspapers since at least 1910 , but became much more frequent in the late 1960s and early $1970 \mathrm{os}$ (Johnstone and Danielson 2001). As Richard Oestreicher (1989; pers. 


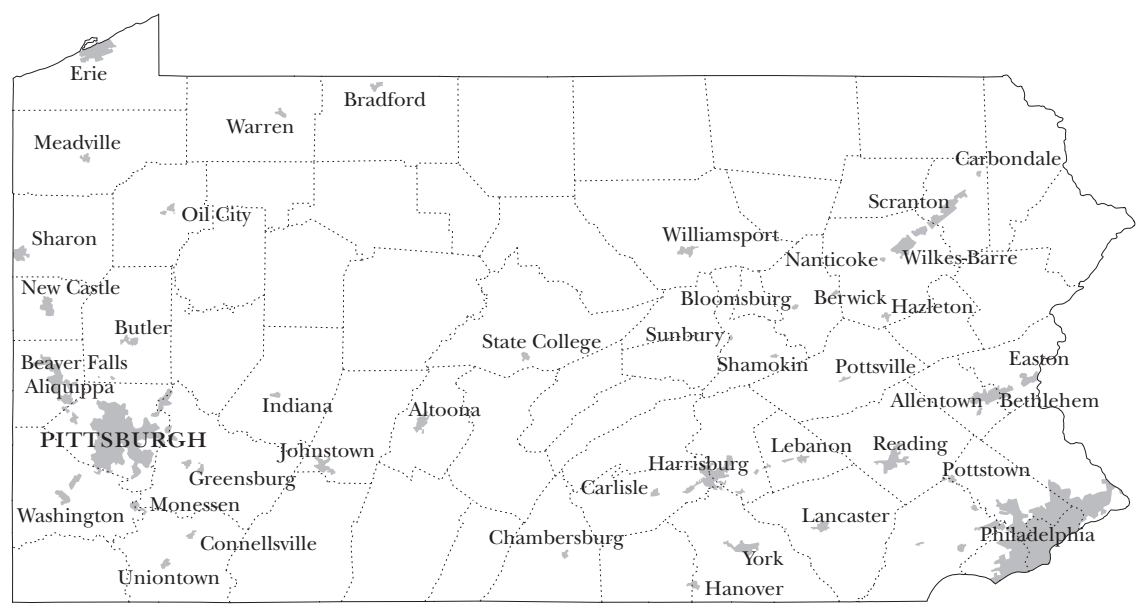

com., 23 Mar. 2002) suggests, this was the era when the grandchildren of the immigrant industrial laborers who had arrived between 1880 and 1920 came of age, no longer speaking the homeland language and with weakened ties to immigrant religions. While their parents and grandparents thought of themselves mainly in ethnic or religious terms, these Pittsburghers began to develop class and regional consciousness. The ground was thus fertile for ways of imagining what it meant to be a working-class Pittsburgher, and local speech provided a powerful resource for this. The existence of local pronunciations and dialect forms that people elsewhere recognized as different and Pittsburghers elsewhere identified with home coincided in the late 1960 and early 1970 with the willingness of a local dialectologist, Robert Parslow, to legitimize these forms in newspaper interviews by explaining their history and referring to them in the aggregate as a dialect.

Linguistic facts provide perhaps the most crucial resources for the popular idea that there is a Pittsburgh dialect. Research by Labov, Ash, and Boberg (forthcoming) shows that there is a set of co-occurring phonological characteristics (merger of /a/ and / $/$ /, fronting of /o/, monophthongization of /aw/, and "Canadian shifting" involving several vowels) that distinguish an area in western Pennsylvania that includes Pittsburgh from other phonological dialect areas in the United States. Other scholarly research about varieties of English spoken in Pittsburgh and southwestern Pennsylvania (Kurath 1949, 35-36; Kurath and McDavid 1961, 17-18; Hankey 1965, 
1972; Brown 1982; Gagnon 1999; McElhinny 1999; Johnstone, Bhasin, and Wittkofski 2002; Kiesling and Wisnosky 2003) identifies other phonological, lexical, and morphosyntactic features whose geographic distribution is limited and includes Pittsburgh. Phonological characteristics include a rounded realization of the merged low back vowel, [॰]; monophthongization of /ay/ before / / / and / $/$ / laxing of tense vowels / $/$ / and $/ \mathrm{u} /$ before $/ \mathrm{r} /$ and $/ \mathrm{l} /$ (so that steel can be realized as [stil]) and elsewhere in at least one word (eagle, realized as [rgal] ); intrusive [r] in some words, and the vocalization of $/ 1 /$. Lexical items identified with the region in the Dictionary of American Regional English (1985-) are almost all traceable either to Scots or to Ulster Scots usage or were originally trade names for things produced locally. They include, in the former category, jag 'tease', nebby 'nosy', slippy 'slippery', and redd up 'clean up', and, in the latter, gumband 'rubber band', jumbo 'bologna sausage', and chipped ham 'thinly sliced ham'. Morphosyntactic characteristics include reversed transitivity in leave and let (so that one might leave the children go out or let the bags on the table), the use of yinz as a second person plural pronoun, and the needs/ wants + past participle construction represented in this shirt needs ironed or the customer wants served. Yes/no questions sometimes end with a fall in intonation rather than the more standard-sounding rise. A discoursemarking feature thought of as local is the sentence-final use of n'at, with a meaning like 'and stuff like that' or 'and so on'.

All of these features are limited in geographic distribution in one way or another, but none is heard only in Pittsburgh or in the Pittsburgh metropolitan area (although monophthongal /aw/ seems to be limited to a fairly small area [Johnstone, Bhasin, and Wittkofski 2002]). Most features of pronunciation which sound local to Pittsburghers are widespread in central and western Pennsylvania, if not throughout the United States, and some of the lexical and morphosyntactic features thought of as local are heard throughout the Ohio Valley or the Midland, Southern, and/or Appalachian dialect areas. Pittsburgh's location at the edges of the North and South Midland and Appalachia results in a large number of sounds, words, and structures that sound nonstandard and can be heard in this area. In local talk about localness, these features function as resources that can be appropriated as people create and reinforce the idea that there is a distinctive local dialect. The contributors to the conversation we are studying may think they are simply describing an already-existing dialect ("Pittsburghese"), but in fact they are helping to construct and reinforce the idea that there is a local dialect, and in talking about the features of this imagined dialect, they are negotiating about vernacular dialect norms. 


\section{THE CONVERSATION}

Our data is part of a moderated discussion hosted by WTAE-TV, Pittsburgh's $\mathrm{ABC}$ affiliate. It is one of a number of discussion boards about topics or events on which the station's news team has reported that can be accessed from the station's home page, http://www.thepittsburghchannel.com. Would-be contributors register with Ibsys (Internet Broadcast Services), the provider of this and other Internet services to a number of U.S. television stations. Posts are submitted to the moderators at Ibsys. ${ }^{2}$

This thread was initiated on 22 March 2002, probably in connection with reporting about an academic workshop on Pittsburgh speech that started that day at Carnegie Mellon University. As noted, one of us (Barbara Johnstone) was co-organizer of the workshop; the other organizer, Scott Kiesling, teaches at the University of Pittsburgh, which circulated a press release about it. One of us may have spoken to a reporter from WTAEthere was a great deal of local and statewide media interest in the workshop, additional evidence of the importance of local speech in Pittsburghers' discourse about themselves-but we did not suggest the idea of an online discussion.

The discussion prompt is "What's your (yunzes') opinion of 'Pittsburghese,' i.e. the dialect indicative of western Pennsylvanians? Also, what's your favorite-and least favorite-term?" But most contributions, particularly at the beginning of the conversation, appear to respond to another, visually more prominent version of the discussion prompt that also appears on the first page: "Is Our Local Dialect Charming or Embarrassing?" Our analysis of the discussion board considers the $91 / 2$-month period from its inception until 1o January 2003. The segment contains 19,253 words; it includes 101 participants, who provide a total of 180 responses. ${ }^{3}$

Our analysis first describes two typical turns near the beginning of the discussion, showing how the contributors establish their right to participate and how they support the claims they make. We suggest that uses and mentions of particular linguistic features can serve as resources in doing these things. Then we focus on vernacular norming in its interactional context. First we ask who has the authority to evaluate the dialect and how the use or mention of its features functions in claiming this authority. We describe in more detail the dialect features participants use or mention in formulating responses and how they describe the sources of their expertise as folk dialectologists, suggesting that the activities of "feature-dropping" (on the analogy of "name-dropping") and "vernacular lexicography" arise in part because they are useful ways of claiming the expertise to evaluate 
other aspects of local life. We also show how feature-dropping can serve as a solidarity-building move and how both feature-dropping and vernacular lexicography can help support evaluative arguments about "Pittsburghese."

Next we turn to vernacular norming in its ideological context, showing how the structure of individual contributions to the discussion, as well as the structure of the discussion as a whole, is scaffolded on widely shared ideas about how places, dialects, and people's identities are connected. The online conversation falls into two distinct parts as a new set of participants starts to replace the first set, so we describe how the parts differ, showing how the shift in the conversation as a whole from talk about talk to talk about place and identity mirrors the way in which these linkages between language, place, and identity are forged and drawn on in individual turns. Local forms that are consonant with participants' ideas about what Pittsburgh and Pittsburghers are like are thus particularly likely to be adduced and reinforced in the discussion.

Finally, we turn to vernacular norming in its historical context. Many of the participants in the discussion are people whose regional identity has been called into question by virtue of their geographic mobility. In particular, local conditions beginning in the 1980 os resulted in a kind of economic diaspora, and over half of the participants in the discussion are people who have moved away from or to the area. Vernacular norms that resonate with their nostalgia are thus particularly likely to be suggested and reinforced, as are forms that have easily comparable counterparts in places where these participants live now.

TWO EARLy COnTRibutions. Particularly at the beginning of the discussion, where responses tend to be directly linked to the discussion question, contributions tend to be quite similar to one another. ${ }^{4}$ These two excerpts exemplify some of the recurring topical and structural features:

1. Hey yunz guys! I am also an ex-burgher well actually (Wish)-ington county. Now in VA, Too. When I first went to college at Edinboro I tried to get rid of my accent because other students and even the professors would point it out. Why is it charming to have accent from one region and not another?

It should not be embarrassing. It doesn't mean we are not intelligent people.

I am proud of being from the Pix-burgh area. I think that the area is an incredible melting pot of many different cultures.

And if its is such an embarressment to talk this way ... if we sounds stupid ... how come i am a univ. prof, and I still say gum bands, pop, and drop the "g" off any word ending in "ing"? [Lyn-byrd, C37] 
2. I never realized I spoke Pittsburgheze until my children became older and asked me why I talk funny. Apparently, our teachers spoke the same way and we were never taught the short vowel sounds. I am too old to correct my speaking now. Many years ago, I lived in Rochester, NYand the people there knew I was from Pittsburgh, and not only that, they knew I was from McKees Rocks. McKees Rocks has their very own thick Pittsburgh accent. Our dialect is charming and I am proud to speak it!!!! [stilesmom, C29]

Their uses of the words "charming" and "embarrassing" show that these participants are both responding to the more prominent version of the prompt: "Is our local dialect charming or embarrassing?" They touch on many of the themes that recur throughout the discussion:

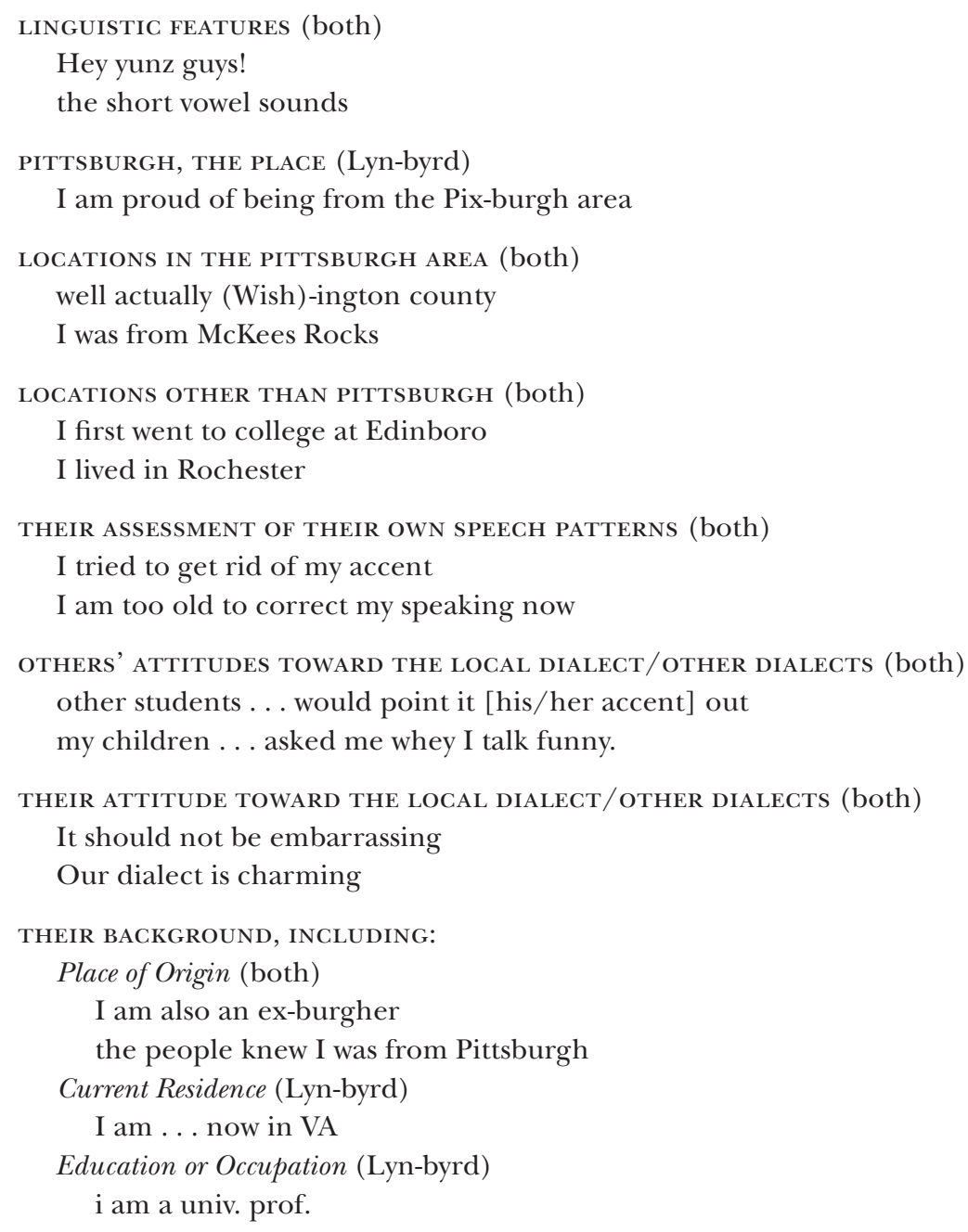


Though there is no strict sequence to the moves participants make, the sequences in the above excerpts are quite typical. Participants often use personal-experience narratives to establish their right to speak by virtue of their "local knowledge" and as inductive support of evaluations of local speech, as suggested by the discussion prompt. Then a deductive rationale for the evaluative claim may be briefly spelled out. Finally, the participants sometimes provide further reasons in support of the claims they have made.

Lyn-byrd, for example, begins by using a local-sounding linguistic item to address the other participants:

Hey yunz guys!

Showing that she or he knows this form of address constitutes a claim to local identity and an offer of rapport-building solidarity with other locals. ${ }^{5}$ Lyn-byrd's subsequent personal-experience narrative validates this claim by showing that she or he counts as local by virtue of personal history:

I am also an ex-burgher well actually (Wish)-ington county. Now in VA, Too. When I first went to college at Edinboro I tried to get rid of my accent because other students and even the professors would point it out.

Once the right to speak by virtue of local knowledge and experience is established, Lyn-byrd moves on to present an argument, suggesting that regional accents in general can be charming:

Why is it charming to have an accent from one region and not another?

This functions as a segue into Lyn-byrd's explicit argument, which begins with a more direct claim, which answers one of the discussion board questions:

It should not be embarrassing. [claim 1]

Lyn-byrd then provides a claim concerning speakers of local dialects, which simultaneously serves as a warrant for the claim that local speech should not be embarrassing:

It doesn't mean we are not intelligent people. [reason A for claim 1]

This sequence of statements can be described as a compressed deductive argument. The statement that immediately follows serves as another warrant for claim 1; here, Lyn-byrd makes an inductive argument:

I am proud to be from the Pix-burgh area. [reason B for claim 1] 
In this argument, Lyn-byrd calls upon personal local experience (again underlined via a local-sounding form, Pix-burgh) to support the claim that people who use local speech should feel the exact opposite of embarrassment, a sense of pride. Lyn-byrd then provides reason i for reason B:

I think that the area is an incredible melting pot of many different cultures. [reason i for reason B]

This sequence of statements is also a compressed argument: if a city is a melting pot of many different cultures, people should be proud of it; Pittsburgh is a melting pot of many cultures; therefore Lyn-byrd is proud of Pittsburgh.

Then Lyn-byrd restates the two prior claims, now in an interrogative conditional form, and closes with evidence presumably supporting both restated assertions. First claim 1 and reason A are restated in a sequence of questions:

And if its is such an embarressment to talk this way ... [claim 1 (restated)] if we sounds stupid... [reason A (restated)]

In providing further evidence for the claim that "talking this way" is not embarrassing, because it does not sound stupid, Lyn-byrd invokes another aspect of identity-occupation and/or educational status.

how come i am a univ prof, and I still say gum bands, pop, and drop the "g" off any word ending in "ing"? [reason B for claim 1]

These example linguistic features ("gum bands," "pop," "drop the 'g"”) reestablish a local identity and hence reinforce Lyn-Byrd's authority on the matter.

Stilesmom makes fewer moves, most of which can also be linked to establishing the authority to speak. The response to the prompt begins with a personal-experience narrative:

I never realized I spoke Pittsburgheze until my children became older and asked me why I talk funny.

In the ensuing elaboration, stilesmom formulates an observation about her or his own speech containing an embedded argument, that "Pittsburghese" lacks vowel sounds that are important to learn:

Apparently, our teachers spoke the same way and we were never taught the short vowel sounds. 
In citing "the short vowel sounds" as absent from "Pittsburghese," stilesmom further establishes his or her local identity. In the next statement, stilesmom synopsizes this personal-experience narrative with an assessment of her or his speech:

I am too old to correct my speaking now.

This assessment elaborates upon the previous one: some features of "Pittsburghese" are not correct.

Stilesmom then moves into a second personal-experience narrative, one that also draws upon another common theme, being recognized as a Pittsburgher by people in other places:

Many years ago, I lived in Rochester, NY and the people there knew I was from Pittsburgh, and not only that, they knew I was from McKees Rocks. McKees Rocks has their very own thick Pittsburgh accent.

This narrative further establishes stilesmom's authenticity as a local, particularly in that it locates her or him in an area with a particularly "thick accent" and shows her or him to be a person with knowledge of local places.

In a direct answer to the discussion question, stilesmom now offers the major claim of the contribution:

Our dialect is charming [claim 1]

Stilesmom's final comment is in part a conclusion to the overall contribution, in part a reason for claim 1:

and I am proud to speak it!!!! [reason A for claim 1]

Stilesmom's local identity at this point is firmly established, so the assessment of his or her own use of local speech can be offered as evidence that local speech is something to be proud of.

VERNACULAR NORMING IN INTERACTIONAL CONTEXT. As we have seen, discussion participants frequently use or mention features they believe to be characteristic of "Pittsburghese." (They also use or talk about features they associate with other regional dialects; we discuss these later.) Table 1 lists all the features that were used as examples of or in performances of "Pittsburghese."

The second person plural form yunz is the most prominent "Pittsburghese" lexical item. ${ }^{6}$ Then come mentions of a local preference for $p o p$ over soda and gumbands for rubber bands. Participants also comment upon the use of redd up 'tidy up', as in I'll redd up that room. Finally, some of the lexical 
TABLE 1

Features of "Pittsburghese" Represented in Conversation

\begin{tabular}{|c|c|c|}
\hline Feature & Example & $\begin{array}{l}\text { No. of } \\
\text { imes Used }\end{array}$ \\
\hline \multicolumn{3}{|l|}{ Pronunciation } \\
\hline Monophthongization of /aw/ & dahn 'down' & 28 \\
\hline Fast speech & $\begin{array}{l}\text { Jeet yet? 'Did you eat yet?; } \\
\text { woonchu 'won't you' }\end{array}$ & 12 \\
\hline Laxing /i/ before /1/ & Stillers 'Steelers' & 11 \\
\hline Intrusive $[\mathrm{r}]$ & warsh & 10 \\
\hline Southern pronunciation of creek & crick & 5 \\
\hline Syllable deletion & 'Burghers, frigerator, hon 'honey' & 4 \\
\hline Vowels: other & melk 'milk'; wooshing 'washing' & 4 \\
\hline Deletions of /r/, /h/, /ð/ & kohner 'corner'; er 'her'; ese 'these' & 3 \\
\hline Nonstandard stress & UM-brella & 3 \\
\hline \multicolumn{3}{|l|}{ Eye dialect (differences are only } \\
\hline orthographic) & 'enuff; ruff & 3 \\
\hline Schwa deletion & ignernt & 2 \\
\hline Stopping of /ð/ & mudder 'mother' & 2 \\
\hline Velarization of / $\mathrm{t} /$ in Pittsburgh & Picksburgh & 2 \\
\hline$-i n g \rightarrow[\mathrm{In}]$ & cookin & 1 \\
\hline Nonstandard assimilation & sammich & 1 \\
\hline Consonants: other & surre 'sure' & 1 \\
\hline Laxing of /i/ in eagle & Giant Iggle & 1 \\
\hline \multicolumn{3}{|l|}{ Lexical/Syntactic Features } \\
\hline yinz/yunz & & 48 \\
\hline pop & & 22 \\
\hline gumbands & & 13 \\
\hline chipped ham & & 6 \\
\hline jumbo & & 6 \\
\hline we was & & 4 \\
\hline needs + past participle & The car needs washed. & 3 \\
\hline \multicolumn{3}{|l|}{ Local Idiom } \\
\hline crack me up & & 1 \\
\hline
\end{tabular}

items that participants use or mention are terms for local products, such as jumbo, originally a brand of lunch meat, later a generic term for 'bologna'. Mentions of syntactic features are much less frequent. Participants mention the plural use of the past singular was and the needs-plus-past-participle construction, as in needs washed.

The most frequently noted "Pittsburghese" phonological feature is the pronunciation of a monophthong [a:] instead of the standard [aw]. This 
feature is sometimes explicitly isolated by participants, who place it in quotes (e.g., "-ahn"), but, more commonly, we find the feature in the word dahntahn. Participants also note the local laxing of /i/ before /1/, most frequently in reference to the local professional football team, the Stillers 'Steelers', or when talking about the "still mills." Concerning consonantal features, participants consistently note the intrusive pronunciation of [r] in wash and Washington. Finally, syllable-level features such as a nonstandard stress (e.g., UM-brella) are mentioned infrequently. Fast-speech constructions, such as D'jeetyet? 'Did you eat yet?', slightly outnumber all other phonological features except /aw/ $\rightarrow$ [a: .

Participants reference these features because doing so is interactionally useful in this conversational context in several ways. First, using or mentioning a feature of "Pittsburghese" is an efficient and effective way to establish oneself as an authority who can credibly make evaluative arguments about the dialect. Local experience is by far the most commonly adduced source of authority to speak in the conversation. A few participants note formal sources for their use or knowledge of "Pittsburghese." One participant (C26), for example, mentions Sam McCool (1982), the author of a "Pittsburghese" dictionary, and another $\left(\mathrm{C}_{1} 6\right)$ refers to an ongoing academic "study" (probably the one being planned at the workshop that led to this discussion). Another participant mentions training in linguistics as a source of knowledge about dialect: "Taking a course in Linguistics in College really opened my eyes to language. Standardization of language is more a political power play of the dominant culture" (C9o). However, the participants most often explain the source of their authority to speak in terms of where they are or where they are from. Some locals describe themselves as speaking the dialect: "I hafta tell yunz I think the way we talk is neat. I can go anywhere in the country and someone immediately knows where I come from . . . I am Pittsburgh through and through" $\left(\mathrm{C}_{5}{ }^{1}\right)$. Other locals explain their knowledge of features in terms of partial exposure: "Well, I was not raised in Pittsburgh, but my sister was raised here" $\left(\mathrm{C}_{4}\right)$. Another group of locals is originally not from Pittsburgh but familiar with local dialect forms: "My sons and I have enjoyed 'collecting' words and expressions particular to this area since we moved here ... in July of 200o" (C17). Conversely, a number of the participants are nonlocals who are originally local: "I am originally from the 'Burgh, Duquesne to be exact and I must say I think our Pittsburgese is the greatest. I live in Northern Minnesota, on the Canadian border" (C67). Other nonlocals often explain personal or causal connections between themselves and speakers of the Pittsburgh dialect: "I'm from Canada eh. My girlfriend lives in the Burgh. She's kind of proud of it's uniqueness, in the dialect department" (C6). 
In addition, the participants mention particular dialect features because doing so is a good way to support their evaluative claims about the dialect and can help build rapport with the other participants. For example, Lyn-byrd (above) uses a local-sounding form, yunz guys, as an address form that builds a rapport with other participants. "Feature-dropping" is also found in Lyn-byrd's personal-experience narrative: "well actually (Wish)-ington county." Additionally, as a way of supporting the explicit argument that the local dialect does not sound stupid, Lyn-byrd describes her or his use of example linguistic features in order to establish herself or himself as a counterexample to the idea that speaking the local dialect is embarrassing: "I still say gum bands, pop, and drop the 'g' off any word ending in 'ing." 'In stilesmom's contribution, the implicit argument about Pittsburghese (that aspects of it are incorrect) is supported by mentioning "short vowel sounds."

When the features dropped into their contributions are not already thought of as characteristics of "Pittsburghese," mentions or uses of them function to suggest new norms; when they are already widely understood to be "Pittsburghese," they function to enforce existing norms. Normenforcement and norm-creation sometimes become explicit when participants engage in what could be called "vernacular lexicography," or explicit talk about whether particular features should or should not be counted as belonging to the dialect. This happens most frequently toward the beginning of the conversation and is exemplified in the following excerpts:

I feel that the non-word "ain't" needs to be included [C22]

... my wife informs me that my use of "whenever" as opposed to just "when," is Pittsburghese $\left[\mathrm{C}_{55}\right]$

"Pop" is not limited to Pittsburgh [C24]

In contributions such as these, the participants explicitly note the normative process they are involved in.

VERNACULAR NORMING IN IDEOLOGICAL CONTEXT. About halfway through the discussion, a new group of participants begins to contribute. Up to this point, participants tend to engage in a collaborative form of argumentation characterized by brief contributions. They also frequently use or mention linguistic features they feel characterize "Pittsburghese" or, by contrast, other regional dialects, tending to focus almost solely on the topic of the local dialect. In contrast, the new participants engage in a consciously argumentative, more combative form of interaction, and they rarely use or mention particular linguistic features. The topics the new 
participants introduce into the discussion shift almost entirely away from evaluations of local dialect toward evaluations of Pittsburgh and what it means to be a Pittsburgher. ${ }^{7}$

Structurally, the conversation turns from single arguments framed as personal comments (like those of Lyn-byrd and stilesmom) toward a more combative mode of argumentation, which is often more consciously identified by the participants as "rational." Each of the participants who effect this change contributes much more often to the conversation than the average participant does and with responses that are often much longer. The greater average number of responses is due in part to the fact that each participant produces multiple contributions that cluster in response to others offering multiple contributions. A typical sequence might follow as such: participant A contributes; participant B responds negatively to A; participant A shoots back a response to B; participant $\mathrm{C}$ comes in to side with B; participant B aligns with C's response; participant D joins to side with $\mathrm{A}$ and attack $\mathrm{B}$ and $\mathrm{C}$; and so on. A participant in the first part of the conversation typically frames a comment in concessive terms and never receives a response:

I think Pittsburghese makes Pittsburgh unique. Ya it does make us sound like a bunch of ignorant red-necks but it is our own little "thing" we have going for us.... [C2]

Those in the second part, however, often express their views more forcefully and are more responsive to those who disagree:

... I was expecting flak. Oreofuchi, there is a difference between the misuse of a word and making up words ... words like dahntahn, red up, worsch, etc. . . . DO NOT EXIST!!!!!!!!!!! I never claimed to be the grammer lady, but I can speak ENGLISH. ... [C87]

Those responding - this participant in particular-are apt to engage in refuting another's logic in great length.

As noted, participants in the second part of the conversation often make lengthy contributions. The contributor with the most responses (15), for example, also offers the longest contribution, which is 708 words long. In contrast, contributions of $15^{\circ}$ words or more are atypical in the first portion of the conversation. Therefore, while participants in the latter portion of the conversation offer fewer than half (82) of the total number of responses (180), their contributions combined account for well over half of the conversation's length, 11,352 of the total 19,253 words.

The content of the conversation also changes. First, there is less use and mention of features of "Pittsburghese." The contributions in the first 
phase together comprise only $41 \%$ of the overall conversation $(7,901$ of 19,253 words). However, participants in this phase use or mention regional features much more often. (Seventy-four percent of the uses or mentions of regional features are in this part of the conversation.) In other words, although the second phase of the conversation accounts for $18 \%$ more words, participants in this phase are only about one-third as likely to use or mention a regional feature.

Throughout the conversation, participants' talk about regional dialects often segues into talk about place. Many participants' talk about "Pittsburghese" or other regional forms is, either explicitly or implicitly, as much or more about Pittsburgh or other places as about dialect. The following participants from relatively early in the conversation move from discussing "Pittsburghese" to commenting on other aspects of Pittsburgh and their relationship to the city:

... [I've] been out of [there] for 17 years ... and still say "melk" instead of milk, gum bands instead of rubber bands, redd up and jaetyet (did you eat yet). I can love Pitt when I come home to eat pirogies, hot roast beefw/fries and gravy and permanti bros sandwiches.... [C20]

I do call rubber bands as they are called here gum bands.... Also yins is my plural of ya'll. I do miss Pittsburgh. ... it's what I call my home! [C21 ]

As these passages suggest, such moves require of the participants very little conversational work: they neither comment on nor forge explicit transitions between the topic of dialect and the topic of place. Discussions of speech forms and other aspects of the locale to which these forms are ascribed (food, feeling at home) appear to entail one another quite naturally.

Brief, one-response interchanges in the first portion of the conversation, such as the following, also mirror this shift in content and show how it is enabled by shared ideas about language, place, and identity:

Pittsburghese is a joke. It's an embarrassing reflection of laziness in a region trapped in a time-warp! [kinglarry, $\mathrm{C}_{1}$ ]

This is in response to kinglarry. . . . You must be from cleveland. . . I feel sorry for you, look around in cleveland and what do you see ... only more cleveland. [dish $5^{\mathrm{o}, \mathrm{C} 1 \mathrm{o}]}$

Kinglarry's contribution links an evaluation of the dialect to an evaluation of the place with recourse to widely shared American linguistic ideology: the idea that, in general, patterns of talk reflect psychological predis- 
positions, and, in particular, nonstandard dialects reflect laziness. ${ }^{8}$ It is this idea, functioning as the implicit premise of the argument, that allows this participant to link the existence of a local dialect with a negative evaluation of the people who speak it, "laziness," and this allows the introduction of a negative evaluation of the region, "trapped in a time-warp." In response, dish $5^{\circ}$ draws on widely shared ideas about how place and identity are linked: people's attitudes are shaped by where they are from ("You must be from cleveland" if you dislike Pittsburgh), partly by virtue of connections between physical geography and mental predispositions (unlike Pittsburgh, Cleveland is flat, which makes it boring, which makes people from there boring).

The shifts in content within these individual contributions and brief exchanges, from discussing "Pittsburghese" to discussing Pittsburgh, mirror a shift in content in the conversation as a whole from "Pittsburghese" to Pittsburgh as the overriding topic of discussion. As Pittsburgh becomes the dominant topic, there is less and less feature-dropping and vernacular lexicography. While participants at the beginning of the conversation may use features or items from "Pittsburghese" or other dialects on the way to making judgments about place, drawing on and creating ideological linkages between dialects and places, participants in the second phase often completely omit discussing dialect and instead simply argue over the merits, faults, and idiosyncrasies of various places and people from those places, drawing on and forging ideological links between places and personal identities. In this sense, the microstructures of many individual contributions, such as the above-cited examples, mirror the macrostructure of the conversation.

For example, these contributors have moved entirely beyond the original topic of local dialect:

... Plus, you have to remember that the truth hurts sometimes and everyone here will have to one day admit that the area is backward and THEN the rest of the country will be more that happy to welcome you into the 21 st Century. ... [pghsucks, Ciog]

pghsucks: I'm pretty amazed that with how much you hate our city, you insist on spending your "valuable" work time ... on a PITTSBURGH website while you LIVE IN PITTSBURGH! If you hate it so much, what are you doing here? [iluvpgh, G 111 ]

A number of participants explicitly comment upon this turn in the conversation. For example, regarding the above-quoted parley between pghsucks and iluvpgh, another participant exclaims: 
It would seem that the topic of the discussion has changed! Rather than the question being "Is our local dialect charming or embarrassing?", it seems now to be "Is Pghsucks dealing with a full deck?" [C $\left.\mathrm{C}_{1} 13\right]$

Others attempt to bring the topic back to the local dialect but are unsuccessful:

For the record, the topic of this discussion is to express one's opinion on the dialect. [C1 19 ]

But back to the dialect discussion. [C 1119$]$

One participant attempts to derail criticisms about Pittsburgh in another's contribution by asking how the contribution relates to the topic of local dialect:

what does your latest post have to do in any way, shape, or form with the manner of speaking employed in western PA? [C1 54 ]

As the conversation progresses it also becomes more interactive. Participants become much more likely to discuss the logic of one another's contributions. They are also much more likely to include in their responses conclusions deriving from another's contribution and to discuss another participant's personal attributes. The tone of the conversation becomes more negative and inflammatory, and people also comment on this:

I think its time to leave this discussion to the mongrels who have taken it over.

... Keep your kielbasa-stuffed bellies lined up to the bar and convince each other how great your washed-up city of the past used to be, back when steel was king (6o or more years ago). [C168]

Participants in the second phase of the conversation may also formulate their first response with moves similar to those made by participants in the earlier phase, such as by providing personal-experience narratives. However, they also draw upon resources from others' responses and comment on aspects of others' identity; overall, they engage in a more elaborate series of moves.

A contribution made by pghsucks99 $\left(\mathrm{C}_{1} 5_{53}\right)$ exemplifies several of the points we have been making. Pghsucks9g begins with a curt explanation of the purpose of the contribution:

Hi. A few comments.

Pghsucks99 then reacts to a claim made by other contributors: 
I am not as miserable person as some who do not know me assume. [claim 1]

Denying the characterization of "a miserable person" is important to pghsucks99 because the question of state of mind bears upon a larger argument: is Pittsburgh a good or bad place to live? Other contributors have pointed out that, in general, pghsucks99 is likely just a miserable person who would dislike any place. Pghsucks99 follows claim 1 with two reasons:

I am quite happy with my life. [reason A for claim 1]

I just do not like it here [in] Pittsburgh. [reason B for claim 1]

Unlike the other authority-building narratives we have examined (Lynbyrd and stilesmom's), pghsucks99 does not draw on local expertise or life history to establish the authority to evaluate the area, but rather on personal opinion. This choice could be seen as an invitation to people who have other opinions to interact. Lyn-byrd's and stilesmom's strategy for establishing local expertise is less interactive.

Then pghsucks99 counters another participant's suggestion that pghsucks99 is not playing by the implicit rules of the activity at hand:

As for abusing a public forum [claim 2], since when is expressing ones Constitutionally protected opinions abusive [reason A for claim 2].

Then a claim from an earlier contribution is reiterated.

I simply criticize a waning city [claim 3]

In the following extended reason for this claim, pghsucks99 refers to statistics about the city:

I urge thoswe of you who deny Pittsburgh descent to go out and investigate future comparisons of cities. Pittsburgh has a constantly declining population and negative growth for jobs in the future. Compare your town with many growing cities and you will see why people are constantly leaving here: lower unemployment, better standard of living, better job market, and potential growth. These are all things that Pittsburgh does NOT have. Sorry to burst your bubble.

In this move, pghsucks99 aligns with more "impartial" sources and thereby transitions from "subjective" assessments of Pittsburgh (such as her or his own) to more "objective" ones. Pghsucks9g lays claim to the authority to evaluate the place by virtue of an argument from external authority rather than one based on personal local expertise, again in contrast to the personal narratives of Lyn-byrd and stilesmom. 
In the next sequence, pghsucks99 anticipates a counterclaim to the assertion that Pittsburgh is a waning city by making claim 4 , that the city cannot be revitalized:

I know there are people who are trying to revitalize this area. Good luck. [claim 4]

In providing a reason for claim 4, pghsucks99 links the place with characteristics of its people:

It will take a long time mainly because of the people in the area and their stubborn resistance to change. [reason A for claim 4]

This move is scaffolded on another implicit ideological premise about how place and identity are connected: all the people in a place have the same characteristics. (It is this idea that enables the sort of stereotyping that both gives rise to and is accomplished in conversations like this.) This idea recurs throughout the discussion, both as a premise linking place and identity and as a premise linking identity and dialect. It results in the construction, throughout the conversation, of a homogeneous population speaking in an invariant way.

In the next sequence, pghsucks99 synopsizes the argument by recalling the two initial counterclaims:

But, I am sure you will be sad that $\mathbf{I}$ intend to leave here as soon as I finish school. [claim 1, restated] So until then, I intend to exercise my free speech rights as much as possible. Remember, your opinions that I am an idiot and unhappy are your opinions too. I am not trying to shut you up. [claim 2, restated]

Finally, pghsucks99 closes with a respectful invitation for responses to the contribution: ${ }^{9}$

Hope to hear from everyone soon.

This closing corresponds to other positive characteristics that pghsucks99 is apparently at pains to establish, an impartial civility ("I am not trying to shut you up") and a rationality impervious to bias ("your opinions . . . are your opinions too"). These can be contrasted with those of Lyn-byrd and stilesmom, who rely much more on building rapport and a sense of solidarity with like-minded participants than on trying to seem logical. Pghsucks99 might describe her or his approach in much the same way a fellow participant, gymguy, describes her or his approach: "I believe that I have ... [approached the topic] in a rational, detached manner" (G119). 
While pghsucks99's contribution is quite lengthy (233 words), it does not touch on the local dialect or other regional dialects. The discussion is now either about regional identity (or lack thereof) or simply Pittsburgh itself. Pghsucks99 discusses herself or himself only to discredit prior claims and does not therefore assess speech patterns or mention others' attitudes toward the local dialect. On the contrary, pghsucks99 instead focuses on others' assessments of Pittsburgh.

The fact that the conversation draws on and creates ideas about how language is connected to place and identity bears on its normative outcome in several ways. Many of the terms chosen in illustrations or performances of "Pittsburghese" are ones that have to do with place and local identity. To give the most obvious example of how place-linked words may be privileged over others, monophthongal /aw/ is represented far more often in town or downtown than in the prepositions in which it is in fact heard more often (due to the frequency of prepositions compared to that of substantives): out, around, about. The fact that "Pittsburghese" is repeatedly linked to local character and lifestyle is reflected in the number of examples of the dialect that have to do with purported characteristics of local people or practices of local life:

On Saturday we worshed the cars and as kids we were given pop for a treat. We have gumbands in our desk, jeat jumbo, redd up, and then there is the all time great one, nnat. [C7o]

The embedding of talk about dialect in talk about place and identity may mean that receding features are preserved longest in forms and contexts that evoke localness.

VERNACULAR NORMING IN HISTORICAL CONTEXT. Why do these people engage in this discussion? As we have suggested above, there are historical and sociolinguistic reasons for enhanced dialect awareness in the Pittsburgh area. For some time conversations about local speech have both drawn on and enhanced Pittsburghers' awareness of local speech, with the side effect of strengthening overt norms for it. Dialect awareness in Pittsburgh is not new, and enhanced attention to local speech has been sparked, as we have suggested, by different combinations of factors at different times. (We have suggested, for example, that the development of regional and class consciousness may have sparked dialect awareness in the 1960 s and 1970s.) Evidence from what happens in the online conversation suggests that geographic mobility and attendant nostalgia for place may be sparking enhanced awareness in the early 2000 . 
Talking about regional dialect is clearly one way of "formulating place" (Schegloff 1972). Theories of place from cultural and humanistic geography (Relph 1976; Mugerauer 1985; Johnstone 1990, forthcoming) suggest that places are experiential and discursive constructs, fundamentally based on individual experience and intersubjectively calibrated through talk. Shared ways of experiencing and orienting to physical space arise from shared ways of evaluating and talking about it. As we have seen, particular turns and exchanges in the conversation as well as the conversation as a whole move from the topic of dialect to that of the place with which the dialect is associated and which it helps to define. In short, people talk about "Pittsburghese" partly because it gives them a way to talk about Pittsburgh.

The evidence suggests, further, that talk about Pittsburgh gives contributors a way to talk about their personal identities. Personal identity recurs as a theme over and over, in the ways people establish their right to participate by showing how they count as Pittsburghers ("I was born and raised in Pittsburgh"; "I am an ex-burgher") and in the frequent ad hominem arguments that rest on people's not being Pittsburghers ("You must be from cleveland"; "If you hate [Pittsburgh] so much, what are you doing here?"). As we have seen, participants often link local identity with personal characteristics like laziness, charm, or friendliness or with a lifestyle they think of as local.

The fact that a great many of the contributors are people who were originally from Pittsburgh but now live elsewhere, or from elsewhere but now in Pittsburgh, reinforces the suggestion that part of the appeal of an online discussion like this is that it provides an outlet for the expression and reinforcement of regional identity in the context of nostalgia. Of the 101 participants, $6_{5}$ provide information in the course of their contributions that allows us to determine whether or not they are geographically mobile with respect to Pittsburgh. (They typically do this quite explicitly, by saying things like "I have lived away from the Burgh for $20+$ years," or "we moved here back in July of 2000.") Of these, 43 (or $43 \%$ of the total participants, although the percentage would probably be higher if we had relevant information about everyone) are Pittsburghers who have lived or are now living elsewhere. Judging from what they say about how long they have been away, many of these are people who moved to the South to find work during the 1980 os, when the rapid decline in steel production in Pittsburgh resulted in severe unemployment. Seven are non-Pittsburghers who live in Pittsburgh. (Several of these are students.) Only 14 of the 65 about whom we can tell appear to have lived in the same place all their lives. Thus at least half of the contributors are people who have had their identities called into question by being regional outsiders, and it is clear 
from the tone of many of the contributions that many of them enjoy the chance to comment on what feels like an important aspect of their personal life histories. Table 2 shows these figures.

One effect of the high percentage of geographically mobile participants on the norm-formation process is that "Pittsburghese" is often described in comparison with other regional dialects—in particular, of course, those the participants have experienced. Twenty percent of the dialect features mentioned or used in the discussion exemplify other dialects, even though the original question elicits no cross-regional comparisons. The participants' own comments suggest that their geographic mobility is one of the major factors producing nonlocal forms against which "Pittsburghese" is defined. The following contributions exemplify how nonlocal dialect forms are typically introduced:

Living here in Richmond, the people's dialect is southern, and they tend to drop the R's off of the end of their words. ie. River=Riva. [C39]

I was born and raised in Pgh., and moved to the south 18 years ago. ... Alas, my kids grew up saying “ya'll” and I still can't get used to it. [C18]

If you lived in Canada ... you would ... make fun of how they don't pronounce the letter $\mathrm{U}$ as in "hows aboot that budday!" [C 1112$]$

The nonlocal items are ascribed to a variety of places: Atlanta, Boston, California, Canada, Chicago, Cleveland, the East, Florida, Ireland, Massachusetts, New York, Philadelphia, South Carolina, the South, Tennessee, Texas, Virginia, West Virginia, and western Pennsylvania. But the ones that are mentioned most frequently are Southern. The only nonlocal pronunciation feature mentioned more than once is the southern raising of $/ \varepsilon /$ to /I/ before nasals in a word such as pen, and the most commonly mentioned

TABLE 2

Geographic Mobility of Discussion Participants

$\begin{array}{lc}\text { Geographic History } & \begin{array}{c}\text { Percentage of } \\ \text { Participants }\end{array} \\ \text { From Pittsburgh, now elsewhere } & 38 \\ \text { From Pittsburgh, lived elsewhere, returned to Pittsburgh } & 5 \\ \text { From elsewhere, live in Pittsburgh now } & 7 \\ \quad \text { ToTaL, geographically mobile } & 50 \\ \text { Lifelong Pittsburgher } & 12 \\ \text { Lifelong non-Pittsburgher } & 2 \\ \quad \text { ToTaL, nonmobile } & 14 \\ \text { Unknown } & 36\end{array}$


nonlocal lexical form is y'all, which is adduced 17 times, far more frequently than any other item from another region.

Geographic mobility may thus be affecting vernacular norm-formation in Pittsburgh in that it calls attention to regional differences in speech and thus encourages comparison of one dialect with another. It may also affect the resulting norms in more specific ways. For example, the second person plural pronoun yinz (in any of its spellings: yunz, younz, yins, and so on) is the most salient and iconic lexical feature of "Pittsburghese." The evidence for this cannot be spelled out in detail here, but its salience is suggested by the fact that yinz appears in every dictionary-like list of local words and that a local term for a local person is yinzer. There may be a connection between this fact and the fact that many ex-Pittsburghers live in an area where there is a different nonstandard second person plural pronoun, y'all, with which yinz can be easily contrasted. This contribution from a former Pittsburgher shows how easily-comparable pronoun forms including yinz may enter the discussion more often than other forms do because they provide an effective, available way of scaffolding an evaluative argument about "Pittsburghese" and Pittsburgh.

*slaps his forehead* Gee, why didn't I think of that? People will start moving back once we CHANGE THE WAYWE TALK! But never mind that "cool" cities like New York and Atlanta still have a significant population that use "youse" and "y'all," respectively, for the second-person plural, becuase "youse" and "y'all" both stem from EDUCATED dialects, right? Pittsburgh will be NOTHING until it contains no dialect whatsoever, right? ... I live in Georgia, the land of "y'all." Why not try living among the "y'allers" for a few years. You'll appreciate the "yunz" a little more. [C93]

Here "appreciating the "yunz" has become a metaphor for appreciating Pittsburgh.

\section{TALK ABOUT TALK AND VERNACULAR NORMING}

To summarize, this conversation illuminates the process of vernacular norm-formation in several ways. First, it illustrates one procedure for relatively overt, metalinguistic dialect norming. As we have shown, participants implicitly and explicitly talk about which particular features "count" as "Pittsburghese" and which do not and about what it means to speak "Pittsburghese." They sometimes negotiate about this, pointing out that items people think are local actually are not or suggesting items they think of as new "contributions" to the dialect. 
Second, the conversation illustrates the fact that norm-formation always arises in a particular discursive situation, for a particular set of social and rhetorical reasons. What the norms end up being is inevitably a function of the situation in which normative activity takes place. A great deal of what goes on in the conversation has to do with establishing who can say authoritative things about "Pittsburghese" and on what grounds. Participants talk directly about and make indirect reference to the sources of expertise that can warrant this sort of normative talk: expertise from scholars and other serious students of the dialect, but mainly the expertise conferred by local experience. You can participate in norm-formation if you are a Pittsburgher, particularly if you "grew up speaking that way." Constructing interpersonal relationships is another important interactional demand in online talk like this, particularly since participants are strangers, and mentioning local-sounding words and phrases can sometimes work to build rapport or, conversely, to set people apart. In this kind of talk, participants also have to support the claims they make; as we have seen, there are various ways of doing this, some of which call forth dialectnormative talk.

Different discursive practices differ in what gives a person authority, what personal relationships are expected to be like and how they are evoked, and how argumentation proceeds. Different constellations of participants, media, and genres may thus give rise to different norms. For example, the activity we have been exploring is "democratic" in a way that other kinds of vernacular norming may not be: anyone with Internet access can participate. It contrasts in this respect with the production of singleauthored folk dictionaries and with the sort of vernacular norming that goes on when sociolinguists talk publicly about regional dialects. It also contrasts with more implicit norming processes that are the focus of much sociolinguistic research, in which the linguistic forms indexing a way of speaking are not explicitly listed and the social meanings of forms are not explicitly articulated.

What the norms end up being is also a function of the meaning-making context in which such normative conversations happen. In this case, as we have argued, people are drawing on and reinforcing familiar ideological tropes linking personal identity to physical place, and place (and particular characteristics of place) to dialect, so that place, identity, and dialect seem naturally linked. Different ideological contexts for norm-formative talk give rise to different ways of arguing for norms and hence different norms. For example, as is often noted, standardization arises in the context of nationalism and the idea that people from different parts of a nation need to share a language, which means that the ideas on which discussions about 
standards are scaffolded have to do with such things as clarity and correctness rather than with such things as nostalgia, personal identity, solidarity, class, and local pride or embarrassment. ${ }^{10}$

It seems likely that explicit normative talk about regional variation will become more common as social and historical conditions continue to give rise to increasingly widespread awareness of differences between community norms and supralocal ones. (One mechanism through which this awareness arises is, as we have seen, geographic mobility.) We thus end with a methodological suggestion. In this conversation and other activities like it, we see vernacular norm-making and norm-focusing in action. We have suggested that the norms that arise and are reinforced in these discursive practices will vary depending on the details of the rhetorical situations in which they occur. This means that sociolinguists who want to understand vernacular norming need to study activities like these, not just their ideological outcomes. Metalinguistic discourse about dialect is important not just as a source of evidence about what people think about variation or about what the variants are, but also as data in its own right. Understanding the talk that gives rise to vernacular norms, in the context of the social and discursive activities in which it arises, requires new modes of analysis that are geared to the study of interaction, including the kinds of discourse analysis we have modeled in this paper.

\section{NOTES}

We are grateful to Alan Juffs for bringing this data to our attention, and to our audience at SECOL in the spring of 2003, two readers for American Speech, and Joan Beal for encouragement and suggestions.

1. "Pittsburghese" is identified mostly with white Pittsburghers. Although some African Americans can be heard to use some of the features identified with it, they tend not to think of themselves or be thought of by others as speaking "Pittsburghese."

2. The moderating policy is described in some detail at http://html.thepittsburgh channel.com/sh/discussions/fineprint.html, but it is not followed very closely. In contravention of the explicit policy, direct personal attacks on other participants do occur ("you idiot snob," "you robot," "i hate you"), as do "words that could be said to demean groups based on identity," such as yinzer. In fact, the establishment of links between words and group identity is precisely what the discussion question could be said to encourage.

3. We refer to our data as a discussion or a conversation, although we have by necessity imposed an arbitrary end point on our data collection. From the perspective of an individual participant, who participates in the discussion 
only sporadically, online discussions of this sort typically lack closure, in any case.

4. Contributions are reproduced as they appeared, without editing. They are labelled with the sender's screen name and/or a number indicating where they appeared in the discussion, so that $\mathrm{C}_{37}$ was the $37_{\text {th }}$ contribution.

5. Since participants choose their screen names, they are free to disguise or misrepresent their sex. Thus we use gender-neutral ways of referring to them.

6. While the word is spelled in a variety of ways, yunz is the most common spelling in this data.

7. Early literature on computer-mediated communication (Kiesler, Siegel, and McGuire 1984) attributed increased rudeness and combativeness in such talk to the depersonalization and focus on the medium encouraged by the fact that people are not face to face. Other online discussions do sometimes seem to shift to a more depersonalized footing in the same way this one does. A full discussion of why this happens is not within the scope of this project.

8. Other speakers link characteristics of dialect with characteristics of speakers in other ways, sometimes completely explicitly: "What makes the dialect charming is obviously a reflection on the quality of the people who speak it" (C113).

9. When they register for the discussion board, participants can choose closing salutations that will automatically be added to all their messages. This may be one such, so it may not be designed for this particular contribution but rather as a general closing from pghsucks99. In either case, it is a choice that invites interaction.

10. The explicit vernacular norm-formation activity we have explored also draws on the discourse of standardization. Participants talk about what sounds "correct" or "educated," for example, and some participants explicitly talk about "standard English." Because participants have been exposed to arguments for the use of standard forms in school, they sometimes talk about "Pittsburghese" in contradistinction to it: if the standard "sounds educated," then Pittsburghers "sound uneducated," for example.

\section{REFERENCES}

Brown, Cynthia. 1982. "A Search for Sound Change: A Look at the Lowering of Tense Vowels before Liquids in the Pittsburgh Area." M.A. thesis, Univ. of Pittsburgh.

Cameron, Deborah. 1995. Verbal Hygiene. London: Routledge.

Coupland, Nikolas. 2001. "Dialect Stylization in Radio Talk." Language in Society 3o: $345^{-75}$.

Dictionary of American Regional English. 1985-. Vol. 1 (A-C), ed. Frederic G. Cassidy. Vols. 2 (D-H) and 3 (I-O), ed. Frederic G. Cassidy and Joan Houston Hall. Vol. 4 (P-Sk), ed. Joan Houston Hall. 4 vols. to date. Cambridge, Mass.: Belknap Press of Harvard Univ. Press. 
Dubois, Sylvie, and Barbara M. Horvath. 2002. "Sounding Cajun: The Rhetorical Use of Dialect in Speech and Writing." American Speech 77: 264-87.

Dyer, Judy. 2002. "We All Speak the Same Round Here': Dialect Levelling in a Scottish-English Community." Journal of Sociolinguistics 6: 99-1 16 .

Gagnon, Christina L. 1999. "Language Attitudes in Pittsburgh: 'Pittsburghese' vs. Standard English.” M.A. thesis, Univ. of Pittsburgh.

Hankey, Clyde T. 1965. "'Tiger,' 'Tagger,' and [ar] in Western Pennsylvania; Diphthongal Variants of $[\varepsilon]$ and $[æ]$ in Western Pennsylvania." American Speech 40 : 226-29.

- 1972. "Notes on West Penn-Ohio Phonology." In Studies in Linguistics in Honor of Raven I. McDavid, Jr., ed. Lawrence M. Davis, 49-61. University: Univ. of Alabama Press.

Johnstone, Barbara. 1990. Stories, Community, and Place: Narratives from Middle America. Bloomington: Indiana Univ. Press.

_. 1999. "Uses of Southern-Sounding Speech by Contemporary Texas Women." In Styling the Other, ed. Ben Rampton, 505-22. Special issue of Journal of Sociolinguistics $3 \cdot 4$.

Forthcoming. "Place, Globalization, and Linguistic Variation." In Sociolinguistic Varation: Critical Reflections, ed. Carmen Fought. Oxford: Oxford Univ. Press.

Johnstone, Barbara, and Judith Mattson Bean. 1997. "Self-Expression and Linguistic Variation." Language in Society 26: 221-46.

Johnstone, Barbara, Neeta Bhasin, and Denise Wittkofski. 2002. “Dahntahn' Pittsburgh: Monophthongal /aw/ and Representations of Localness in Southwestern Pennsylvania." American Speech 77: 148-66.

Johnstone, Barbara, and Andrew Danielson. 2001. "Pittsburghese' in the Daily Papers, 1910-2001: Historical Sources of Ideology about Variation.” Paper presented at the 3oth annual conference on New Ways of Analyzing Variation (NWAV 30), Raleigh, N.C., 11-14 Oct.

Kiesler, Sara, Jane Siegel, and Timothy W. McGuire. 1984. "Social Psychological Aspects of Computer-Mediated Communication." American Psychologist 39: $1123-34$.

Kiesling, Scott F., and Marc Wisnosky. 2003. "Competing Norms, Heritage Prestige, and the Decline of /aw/-Monophthongization in Pittsburgh.” Paper presented at the $32 \mathrm{~d}$ annual conference on New Ways of Analyzing Variation (NWAV 32), Philadelphia, 9-12 Oct.

Kurath, Hans. 1949. A Word Geography of the Eastern United States. Ann Arbor: Univ. of Michigan Press.

Kurath, Hans, and Raven I. McDavid, Jr. 1961. The Pronunciation of English in the Atlantic States: Based upon the Collections of the Linguistics Atlas of the Eastern United States. Ann Arbor: Univ. of Michigan Press.

Labov, William. 1972. Sociolinguistic Patterns. Philadelphia: Univ. of Pennsylvania Press. 
Labov, William, Sharon Ash, and Charles Boberg. Forthcoming. Atlas of North American English. Berlin: de Gruyter. Available from http://www.ling.upenn.edu/ phono_atlas.

Lane, Lisa Ann. 1998. "Emergence and Transformation of a Dialect: Thyborønsk (Danish)." Ph.D. diss., Univ. of Chicago.

Lippi-Green, Rosina. 1997. English with an Accent: Language, Ideology, and Discrimination in the United States. London: Routledge.

McCool, Sam. 1982. Sam McCool's New Pittsburghese: How to Speak Like a Pittsburgher. Pittsburgh, Pa.: Hayford.

McElhinny, Bonnie. 1999. "More on the Third Dialect of English: Linguistic Constraints on the Use of Three Phonological Variables in Pittsburgh." Language Variation and Change 1 1: 171-95.

Milroy, James. 1992. Linguistic Variation and Change: On the Historical Sociolinguistics of English. Oxford: Blackwell.

- 2001. "Language Ideologies and the Consequences of Standardization." Journal of Sociolinguistics 5: 530-55.

Milroy, James, and Lesley Milroy. ${ }^{985}$. Authority in Language: Investigating Language Prescription and Standardisation. London: Routledge.

Montgomery, Michael, and Margaret Mishoe. 1999. "He Bes Took Up with a Yankee Girl and Moved Up There to New York': The Verb bes in the Carolinas and Its History." American Speech 74: 240-81.

Mugerauer, Robert. 1985. "Language and the Emergence of the Environment." In Dwelling, Place, and Environment: Towards a Phenomenology of Person and World, ed. David Seamon and Robert Mugerauer, 51-7o. Dordrecht: Martinus Nijhoff.

Oestreicher, Richard. 1989. "Working-Class Formation, Development, and Consciousness in Pittsburgh, 1790-196o." In City at the Point: Essays on the Social History of Pittsburgh, ed. Samuel P. Hays, 111-50. Pittsburgh, Pa.: Univ. of Pittsburgh Press.

Preston, Dennis R. 1989. Perceptual Dialectology: Nonlinguists' Views of Areal Linguistics. Dordrecht: Foris.

— - ed. 1999. Handbook of Perceptual Dialectology. Vol. 1. Amsterdam: Benjamins.

Relph, E. 1976. Place and Placelessness. London: Pion.

Schegloff, Emmanuel A. 1972. "Notes on a Conversational Practice: Formulating Place." In Studies in Social Interaction, ed. David Sudnow, 75-119. New York: Free Press.

Schilling-Estes, Natalie. 1998. "Investigating 'Self-Conscious' Speech: The Performance Register in Ocracoke English." Language in Society 27: 53-83.

Wolfram, Walt. 2003. "On the Construction of Vernacular Dialect Norms." In Sociolinguistics: The Essential Readings, ed. Christina Bratt Paulston and G. Richard Tucker, 251-71. Malden, Mass.: Blackwell.

Zelinsky, Wilbur. 1995. "Cultural Geography." In A Geography of Pennsylvania, ed. E. Willard Miller, 132-53. University Park: Pennsylvania State Univ. Press. 